Kansas State University Libraries

New Prairie Press

\title{
TWO-FACTOR AGRICULTURAL EXPERIMENT WITH REPEATED MEASURES ON ONE FACTOR IN A COMPLETE RANDOMIZED DESIGN
}

\author{
Armando Garsd \\ María del C. Fabrizio \\ María V. López
}

Follow this and additional works at: https://newprairiepress.org/agstatconference

Part of the Agriculture Commons, and the Applied Statistics Commons

\section{(c) (1) $\Theta$}

This work is licensed under a Creative Commons Attribution-Noncommercial-No Derivative Works 4.0 License.

\section{Recommended Citation}

Garsd, Armando; Fabrizio, María del C.; and López, María V. (1995). "TWO-FACTOR AGRICULTURAL EXPERIMENT WITH REPEATED MEASURES ON ONE FACTOR IN A COMPLETE RANDOMIZED DESIGN," Conference on Applied Statistics in Agriculture. https://doi.org/10.4148/2475-7772.1340

This is brought to you for free and open access by the Conferences at New Prairie Press. It has been accepted for inclusion in Conference on Applied Statistics in Agriculture by an authorized administrator of New Prairie Press. For more information, please contact cads@k-state.edu. 


\title{
TWO-FACTOR AGRICULTURAI EXPERIMENT WITH REPEATED MEASURES ON ONE
} FACTOR IN A COMPLETE RANDOMIZED DESIGN

Garsd, Armando; Fabrizio, María del C.; López, María V. Department of Statistics, School of Agriculture, University of Buenos Aires

\begin{abstract}
A typical agricultural experiment involves comparisons of several treatments at different points in time. The ensuing lack of independence between observations of the same experimental unit may then impair the attainment of statistical significance by the standard analysis of variance, and calls for the application of more powerful methods. This paper addresses one such method, the so-called two-factor experiment with repeated measures on one factor. We discuss the adequacy of this model in the context of three concrete examples drawn from agricultural experimentation.
\end{abstract}

Keywords: Two-factor ANOVA, statistical power, multivariate analysis, repeated measures.

\section{INTRODUCTION}

Consider the two-factor agricultural experiment with repeated measures on one factor, such as time. The layout for this design is presented in Table 1.

For this problem, the univariate mode of analysis (ANOVA) is generally more powerful than the multivariate approach, provided the assumptions underlying the univariate model are valid and the hypothesis under consideration involves time (Arnold, 1981; Crowder and Hand, 1990; Rouanet and Lepine, 1970; Rogan, Keselman and Mendoza, 1979). Otherwise, specific cases may favor the significance of the multivariate approach, although the apparent increase in power may also indicate an increase in type I error rate. We present examples, in fact counterexamples, addressing these cases.

The statistical model for the univariate ANOVA is

$$
X_{i j k}=\mu+\beta_{j}+\pi_{j k}+\alpha_{i}+(\alpha \beta)_{i j}+\varepsilon_{i j k} \quad \text { (1) }
$$

where $\mu$ is the mean level, the $\alpha_{i}$ are the marginal time effects across treatments, the $\beta_{j}$ are the marginal means for the treatments 
across time, the $\pi_{j k}$ are the average deviations of the kth unit about the marginal mean for the jth treatment group, the $(\alpha \beta)_{i j}$ represent the interactive time dependent magnitudes of the treatment effect for the jth group at the ith time. For different

$k$ the $\pi_{j k}$ are uncorrelated. For given $k$ the correlations between the $\pi_{j k}$ are constant. The $\varepsilon_{i j k}$ are all uncorrelated and the $\varepsilon_{i j k}$ and $\pi_{j k}$ are also uncorrelated. Furthermore, the $\varepsilon_{i j k}$ and $\pi_{j k}$ are normally distributed. The validity of (1) depends on the equality of the covariance matrices of the orthonormal contrasts across treatments, and for time-related hypotheses on sphericity

$\left(\operatorname{Var}\left(\mathrm{X}_{i j k}-\mathrm{X}_{i j \mathrm{j}}\right)=\right.$ constant). Sphericity is usually assessed through a sphericity factor $\varepsilon$, a function of the elements of the common covariance matrix (Winner, 1971). If sphericity holds, $\varepsilon$ equals 1 . Otherwise, $\varepsilon$ is smaller than 1 . Sphericity can be tested with Mauchly's test (Morrison, 1976). If sphericity is rejected, then the standard $F$ value for testing time-related hypothesis can be reduced according to the Greenhouse-Geisser or Huynh-Feldt corrections (Winer, 1971). Alternatively, for each a priori contrast of interest one can perform a separate-error $F$ test. That is, an $F$ test using only the covariance matrix relevant to the specific contrast (Maxwell, 1980; Boick, 1981).

In this paper the multivariate approach is based on Hotelling's $\mathrm{T}^{2}$ or Wilk's $\Delta$ (Morrison, 1976). Provided that normality and homogeneity of the (common) covariance matrix hold, the multivariate method is always a legitimate method to adopt.

The examples that follow are based on real experiments but with some data modified to emphasize main points. All computations were performed in SAS (1988).

\section{Example 1}

Yield ( $\mathrm{kg} / \mathrm{plot}$ ) of cherry tomatoes (Licopersicum esculentum var. cereciforme) from two different training systems: one-stem system vs four-stem system. The data from this experiment are presented in Table 2 and results of the statistical analyses are shown in Table 3 .

Table 3 shows no significant interaction. Consider then the dates' main effect (also shown in Table 3). It is well known from the literature (see, for example, Crowder and Hand, 1990) that under $\mathrm{H}_{0}$ and lack of sphericity the univariate test tends to reject too many $\mathrm{H}_{0}$ 's (which is not the case here). As Table 3 shows, the 
Greenhouse-Geisser correction depresses the original univariate Fvalue, making results even less significant under the univariate approach. Therefore, under $\mathrm{H}_{1}$ and non-sphericity the multivariate test may have greater power than the univariate method. However, suppose one is a priori interested in a contrast between the first measurement versus the forth. It can be shown that the resulting $F$ value for that specific contrast is statistically significant at $p<0.02$. This result is more in line with the significance of the multivariate approach presented in the Table.

\section{Example 2}

A study was conducted to correct copper deficiency in calves. Calves were randomly assigned to one of three treatments, homeopathic copper supplement or standard commercial supplement or control. Body weights $(\mathrm{kg})$ of treated calves were measured on three different occasions. The resulting data set is presented in Table 4 and the results of statistical analyses are shown in Table 5.

Table 5 points to the existence of a significant interaction $(\alpha=0.05)$ via multivariate approach. Notice that a very small difference in the $p$ value can lead to a substantially different decision. The detection of a significant interaction would call for testing the significance of the simple main effects rather than the overall main effects.

As Table 5 shows both tests have the same numerator degrees of freedom, but the univariate tests has greater denominator degrees of freedom. Under $\mathrm{H}_{0}$ and sphericity the multivariate test generally tends to underestimate $F$ (which is not the case here).

It is conceivable that in this particular instance Mauchly's test failed to reject a false $\mathrm{H}_{0}$ (sphericity). Mauchly's test is not always powerful (Huynh and Mandeville, 1979). If the underlying model is not spherical relevant comments made above for example 1 would also apply here. The same is true if $\mathrm{H}_{1}$ holds.

\section{Example 3}

An experiment was carried out to improve weight of pigs. The data set in Table 6 represents measurements $(\mathrm{kg})$ on six different times. The results of statistical analyses are shown in Table 7.

The hypothesis of overall treatment differences does not involve time. Under the usual assumptions univariate and multivariate tests 
are always valid, regardless of the sphericity condition (Arnold, 1981), but the multivariate method may be more powerful.

Notice that unlike time-related hypotheses, the power of this type of hypothesis under the univariate procedure decreases as intraclass correlation increases (Arnold, 1981). Therefore, under the univariate model the intraclass correlation affects the power of these two types of hypotheses in opposite directions.

\section{DISCUSSION}

For time-related hypotheses the univariate test averages estimated variances of all contrasts. The resulting tests on individual contrasts may then have denominators which are too small or too large. Thus the counterexamples present here.

Simulation results in the literature indicate that the magnitude of the loss in power comparing multivariate and univariate tests ranges from 5 to 11 percent if the sphericity assumption is approximately correct (Mendoza et al, 1974). However, if $\varepsilon<0.75$ the multivariate procedures are consistently more powerful than their univariate alternatives, with the loss in univariate power ranging from 7 to 21 percent. According to Rogan et al (1979) departures from the sphericity assumption cause small changes in the nominal type I errors. These authors also investigated the effect of departures from the normality assumption on type $I$ and type II errors. It should be noted that if the distribution is normal the increase in power of the $T$ test cannot be due to an increase of type I error, since the actual level of this test is always $\leq \alpha$ under normality (Morrison, 1976). However, if the distribution is not normal, results from these simulation studies show that the increase in power of multivariate procedures may also indicate an increase in the type I error ranging from 0.045 to 0.059 for $a$ nominal 0.05 level.

Crowder and Hand (1990) suggest that if one has strong prior reasons for believing that sphericity holds then one should perform the standard unmodified F-test, and if not then one should perform either a modified F-test or a multivariate test.

Our suggestion stems from the ideas of Rouanet and Lepine (1970) and Boick (1981): If possible, perform the multivariate test (testing interactions perhaps at $10 \%$ ). If results are significant then stop. If results are not significant, perform Mauchly's test and estimate the covariance matrix of contrasts. Examine all relevant 
facts. Adapt the univariate test. Use error term appropriate for each contrast.

\section{SUMMARY}

We have discussed the two-factor experiment with repeated measures on one factor. We introduced three counterexamples involving higher actual significance for the multivariate testing. We have proposed an approach stemming from Boick's work on separate $F$ tests. We conclude that no automatic procedure is likely to produce the right choice of testing approach. Rather, all relevant facts, univariate, multivariate and Mauchly'test must be taking into account.

\section{REFERENCES}

Arnold, S. 1981. The theory of linear models and multivariate analysis. John Wiley and Sons. New York. pp. 217, 377, 432.

Boick, R. 1981. A priori tests in repeated measures designs: Effects of nonsphericity. Psychometrika, 46: 241-255.

Crowder, M. J., and Hand, D. J. 1990. Analysis of repeated measures. Chapman and Hall, pp. 50-56.

Huynh, H. and Mandeville, G. H. 1979. Validity conditions in repeated measures designs. Psychological Bulletin. 86: 964-973.

Maxwell, S. E. 1980. Pairwise multiple comparisons in repeated measures designs. Journal of Educational Statistics, 5: 269-287.

Mendoza, J. L. Toothaker, L. E., and Nicewander, W. A. 1974. A Monte Carlo comparison of the univariate and multivariate methods for the groups by trials repeated measures design. Multivariate Behavioral Research, 9: 165-177.

Morrison, D. 1976. Multivariate statistical methods. McGraw-Hill, New York. pp. 134, 141-153, 250-253.

Rogan, J. C., Keselman, H. J. and Mendoza, J. L. 1979. Analysis of repeated measurements. British Journal of Mathematical and Statistical Psychology, 32: 269-286. 
Rouanet, H. and Lepine, D. 1970. Comparison between treatments in a repeated-measurement design: ANOVA and multivariate methods. The British Journal of Mathematical and Statistical Psychology, 23: 147-163.

SAS System. 1988. SAS Institute Inc., SAS/STAT user's guide, release 6.03 edition, Cary, NC, USA.

Winer, B. J. 1971. Statistical principles in experimental design. Second edition. McGraw-Hill. New York, pp. 514-539. 
Table 1. Layout of two-factor ANOVA with repeated measures on one factor

\begin{tabular}{|c|c|c|c|c|c|c|c|}
\hline \multirow{2}{*}{ Time } & \multicolumn{3}{|c|}{ Treatment 1 } & \multicolumn{3}{c|}{ Treatment 2 } & $\ldots$ \\
\cline { 2 - 8 } & \multicolumn{3}{|c|}{ Units } & \multicolumn{3}{c|}{ Units } & $\ldots$ \\
\cline { 2 - 8 } & 1 & 2 & $\ldots$ & 1 & 2 & & \\
\hline 1 & & & & & & & \\
\hline 2 & & & & & & & \\
\hline$\ldots$ & & & & & & & \\
\hline
\end{tabular}

Table 2: Yield ( $\mathrm{kg} / \mathrm{plot}$ ) cherry tomatoes from two different training systems on different dates (Example 1)

\begin{tabular}{|c|c|c|c|c|c|c|c|c|c|c|c|c|c|c|}
\hline & \multicolumn{7}{|c|}{ Treat. 1} & \multicolumn{7}{|c|}{ Treat. 2} \\
\hline$D$ & 01 & 02 & 03 & 04 & 05 & 06 & 07 & 01 & 02 & 03 & 04 & 05 & 06 & 07 \\
\hline 1 & 1.896 & 1.545 & 1.955 & 1.662 & 1.721 & 2.072 & 1.545 & 2.130 & 1.311 & 2.130 & 1.838 & 1.779 & 0.960 & 1.253 \\
\hline 2 & 2.072 & 1.545 & 2.013 & 1.896 & 1.779 & 1.838 & 1.545 & 1.955 & 1.662 & 2.130 & 1.896 & 1.955 & 0.902 & 1.253 \\
\hline 3 & 1.896 & 1.779 & 2.130 & 1.838 & 1.779 & 0.609 & 1.253 & 1.779 & 1.545 & 2.130 & 1.896 & 1.896 & 0.609 & 1.838 \\
\hline 4 & 2.364 & 1.838 & 2.130 & 1.721 & 2.013 & 1.896 & 2.013 & 2.247 & 1.545 & 2.364 & 2.072 & 1.662 & 0.785 & 1.838 \\
\hline Av & 2.057 & 1.677 & 2.057 & 1.779 & 1.823 & 1.604 & 1.589 & 2.028 & 1.516 & 2.189 & 1.926 & 1.823 & 0.814 & 1.546 \\
\hline & & & & & & & & & & & & & & \\
\hline
\end{tabular}

D: date: 1: 05-01-92, 2: 05-15-92, 3: 05-30-92, 4: 06-01-92. Treat.1: one-stem system treatment. Treat.2: four-stem system treatment. Av: Arithmetic average. Ui: experimental unit.

Table 3. Results from example 1

\begin{tabular}{|c|c|c|c|c|c|}
\hline Effect & Method & Num.df & Den.df & F & P \\
\hline \multirow{2}{*}{$\begin{array}{c}\text { Treatment by date } \\
\text { interaction }\end{array}$} & Onivariate & 3 & 36 & $0.87 \star$ & 0.44 \\
\cline { 2 - 7 } & Multivariate & 3 & 10 & 0.87 & 0.49 \\
\hline Dates & Onivariate & 3 & 36 & $2.66 \star$ & 0.10 \\
\hline & Multivariate & 3 & 10 & 7.62 & 0.01 \\
\hline
\end{tabular}

Num.df, Den.df: numerator and denominator degrees of freedom, respectively.

* Greenhouse-Geisser corrected F statistic. Mauchly's test: $p<0.001$. 
Table 4. Data from trial on the incidence of copper in calves' weight (Example 2)

\begin{tabular}{|c|c|c|c|c|c|c|c|c|c|c|c|c|c|c|c|}
\hline & \multicolumn{5}{|c|}{ C } & \multicolumn{5}{|c|}{$\mathbf{s}$} & \multicolumn{5}{|c|}{$\mathbf{H}$} \\
\hline 0 & 01 & 02 & 03 & 04 & 05 & 01 & $\mathrm{0} 2$ & 03 & 04 & 05 & 01 & 02 & 03 & 04 & 05 \\
\hline 1 & 50 & 90 & 75 & 60 & 59 & 77 & 65 & 78 & 60 & 85 & 93 & 56 & 60 & 98 & 80 \\
\hline 2 & 59 & 112 & 84 & 76 & 69 & 94 & 87 & 92 & 78 & 96 & 120.3 & 75.2 & 81.2 & 119.3 & 106.3 \\
\hline 3 & 87 & 135 & 106 & 100 & 94 & 115 & 116 & 118 & 104 & 120 & 142.6 & 97.7 & 92.7 & 147.6 & 125.6 \\
\hline \multirow[t]{2}{*}{ Av } & 65.3 & 112.3 & 88.3 & 78.7 & 74 & 95.3 & 89.3 & 96 & 80.7 & 100.3 & 118.6 & 76.3 & 78 & 121.6 & 104 \\
\hline & \multicolumn{5}{|c|}{ Av: 83.7} & \multicolumn{5}{|c|}{ Av: 92.3} & \multicolumn{5}{|c|}{ Av: 99.7} \\
\hline
\end{tabular}

0: occasions: 1: 11-27-91, 2: 12-26-91, 3: 02-01-92. C: Control. S: Standard commercial supplement. H: Homeopathic supplement. Av: Arithmetic average. Ui: Experimental unit.

Table 5. Results from example 2

\begin{tabular}{|c|c|c|c|c|c|}
\hline Effect & Method & Num.df & Den.df & F & P \\
\hline $\begin{array}{c}\text { Treatment by occasion } \\
\text { interaction }\end{array}$ & Onivariate & 4 & 24 & 2.69 & 0.06 \\
\cline { 2 - 6 } & Multivariate & 4 & 22 & 2.96 & 0.04 \\
\hline
\end{tabular}

Num.df, Den.df: numerator and denominator degrees of freedom, respectively. Mauchly's test: $p=0.18$

Table 6. Weight of pigs (kg) on six occasions (Example 3)

\begin{tabular}{|c|c|c|c|c|c|c|c|c|c|c|c|c|c|c|c|}
\hline & \multicolumn{5}{|c|}{ Treat. 1} & \multicolumn{5}{|c|}{ Treat. 2} & \multicolumn{5}{|c|}{ Treat. 3} \\
\hline$T$ & 01 & 02 & 03 & 04 & 05 & 01 & U2 & U3 & U4 & 05 & 01 & 02 & 03 & 04 & 05 \\
\hline 1 & 40.6 & 44.3 & 37.5 & 49.9 & 48.3 & 58.8 & 36.0 & 53.0 & 60.7 & 55.4 & 53.3 & 53.9 & 47.7 & 68.4 & 45.9 \\
\hline 2 & 42.2 & 74.6 & 63.8 & 67.5 & 54.5 & 73.0 & 48.3 & 76.1 & 82.3 & 71.5 & 73.0 & 66.9 & 57.6 & 74.6 & 53.9 \\
\hline 3 & 57.6 & 88.5 & 79.2 & 83.5 & 69.9 & 74.6 & 65.6 & 75.8 & 88.5 & 82.6 & 92.2 & 82.0 & 75.5 & 79.2 & 66.9 \\
\hline 4 & 55.7 & 84.1 & 84.5 & 80.1 & 63.1 & 61.9 & 49.6 & 80.8 & 96.8 & 86.9 & 92.2 & 72.1 & 71.5 & 85.7 & 61.9 \\
\hline 5 & 34.7 & 67.5 & 79.8 & 88.8 & 73.6 & 70.6 & 75.2 & 78.0 & 107.3 & 100.5 & 95.3 & 75.5 & 78.0 & 95.6 & 64.4 \\
\hline 6 & 44.0 & 81.4 & 91.2 & 89.1 & 78.0 & 84.5 & 72.7 & 109.2 & 116.9 & 108.5 & 107.0 & 88.2 & 86.9 & 100.5 & 80.1 \\
\hline$\overline{A v}$ & 45.8 & 73.4 & 72.7 & 76.5 & 64.6 & 70.6 & 57.9 & 78.8 & 92.1 & 84.2 & 85.5 & 73.1 & 69.5 & 84.0 & 62.2 \\
\hline & & & & & & & & & & & & & & & \\
\hline
\end{tabular}

T: Times: 1: 10-01-93; 2: 10-15-93; 3:10-25-93; 4: 10-30-93; 5: 11-05-93; 6: 11-15-93. Treat.1: Treatment 1. Treat.2: Treatment 2. Treat.3: Treatment 3. Av: Arithmetic average. Ui: experimental unit. 
Table 7. Results from example 3

\begin{tabular}{|c|c|c|c|c|c|}
\hline Effect & Method & Num.df & Den.df & F & P \\
\hline \multirow{2}{*}{$\begin{array}{c}\text { Treatment by date } \\
\text { interaction }\end{array}$} & Onivariate & 10 & 60 & 1.71 & 0.16 \\
\cline { 2 - 6 } & Multivariate & 10 & 16 & 2.14 & 0.08 \\
\hline \multirow{2}{*}{ Treatment } & Onivariate & 2 & 12 & 1.03 & 0.39 \\
\cline { 2 - 6 } & Multivariate & 12 & 14 & 2.56 & 0.048 \\
\hline
\end{tabular}

Num.df, Den.df: numerator and denominator degrees of freedom, respectively.

* Greenhouse-Geisser corrected F statistic. Mauchly's test: $p=0.009$. 